\title{
O CONTEXTO DA REESTRUTURAÇÃO PRODUTIVA EM FÁBRICAS DA INDÚSTRIA DE LINHA BRANCA: UM DISCURSO PARA A RENOVAÇÃO DO CONTROLE SOCIAL
}

The context of productive restructuring in the industry of white goods: a speech to the renewal of social control

Giovanna Pezarico

\begin{abstract}
Resumo
Este artigo tem por objetivo apresentar análises resultantes de pesquisa qualitativa e interpretativa realizada nos anos de 2006 e 2007, sobre as relações de transformação dos saberes e poderes, produzidas no contexto da reestruturação produtiva de uma empresa da indústria de linha branca, localizada na região Sudoeste do Estado do Paraná, Brasil. A abordagem metodológica para tal análise se divide em três momentos. Num primeiro momento analisou-se o discurso em torno da reestruturação produtiva como um discurso voltado para a renovação do controle social em diálogo com as transformações do contexto da produção. Num segundo momento, passou-se a analisar as transformações experimentadas pelas fábricas no contexto da reestruturação produtiva e suas decorrências. O terceiro momento trata das manifestações dos saberes e poderes mediados pela tecnologia nas das fábricas analisadas, principalmente no que tange aos trabalhadores de origem rural, o trabalho feminino e a relação tempoespaço.
\end{abstract}

Palavras-chave: Reestruturação produtiva; Linha branca; Sudoeste do Paraná.

\section{Abstract}

This paper aims at presenting some analyses that resulted from a qualitative 
and interpretive survey - conducted in 2006 and 2007 - on the relationship between knowledge and power changes undergone in the context of the restructuring of production of a white household appliance industry established in the Southeast Region of Paraná State, in Brazil. The methodological procedures are divided into three phases: 1) Analysis of the discourse on the restructuring of production, as a discourse directed at the renewal of social control, in tandem with changes in the production context; 2) Analysis of changes experienced in factories, within the context of production restructuring and its consequences; 3) Analysis of knowledge and power manifestations mediated by technology within the factories analyzed, mainly in relation to rural workers, to work done by women and to the time-space relationship.

Keywords: Southeast region of Parana; Restructuring production; Renewal of social control.

\section{Introdução}

Este artigo tem por objetivo apresentar algumas análises resultantes de pesquisa qualitativa e interpretativa, inserida nas discussões da temática Tecnologia e Trabalho. Tal estudo teve por escopo apresentar como se estabelecem as relações entre saberes e poderes mediados pela tecnologia, no contexto da reestruturação produtiva de uma empresa composta por duas fábricas da indústria de linha branca, localizadas no Estado do Paraná, Brasil. Especificamente, as fábricas concentram-se na produção de fogões, sendo que uma atua na produção de fogões a lenha (denominada de Fábrica B) e a outra, na produção de fogões a gás (denominada de Fábrica A). A abordagem para tal análise de divide em dois momentos. Num primeiro momento analisou-se o discurso em torno da reestruturação produtiva como um discurso também voltado para a renovação do controle social em diálogo com as transformações do contexto da produção. Num segundo momento, passou-se a analisar as principais transformações experimentadas pelas fábricas no contexto de sua reestruturação produtiva. O terceiro momento trata das manifestações acerca dos saberes e poderes mediados pela tecnologia no contexto da reestruturação produtiva nas fábricas analisadas. 
Para que tal estudo pudesse ser desenvolvido, alguns aprofundamentos foram essenciais para a construção das análises: demarcações acerca das concepções de tecnologia no plano teórico; o viés discursivo referente aos processos objetivados à produção/inculcamento e resistência às normas e à produção de verdades; e por fim, a compreensão dos discursos articulados aos mecanismos disciplinares e as tecnologias do poder, dos signos, da produção, do "eu" no contexto da materialidade em diálogo com o imaginário social.

Assim, o objeto do referido estudo está relacionado às decorrências das transformações tecnológicas e o trabalho, no contexto da constituição dos sujeitos. As transformações tecnológicas, no decorrer do tempo, têm sido acompanhadas de transformações nos processos organizacionais. A introdução intensa das tecnologias no trabalho, tanto da maquinaria quanto dos processos de gestão e controle da produção, bem como de técnicas para o esquadrinhamento dos indivíduos, implicou num processo de construção de saberes sobre o corpo e a alma. A problematização acerca do sujeito tornou-se questão central para produzir respostas "verdadeiras" para as complexidades da sociedade industrial e capitalista. Saberes considerados prementes surgiram ou transformaram-se no intuito de garantir a sedimentação e o controle do modelo social pretendido, enquanto muitos outros foram desqualificados.

Logo, é possível depreender que estes saberes também repercutiram para a formação de uma economia política do poder que utiliza as mais diversas estratégias e táticas, relacionadas ou não, a discursos descontínuos, de mecanismos de disciplina, do exame e da normalização. É nesta microfísica do poder, minuciosamente explorada por Michel Foucault que alguns espaços constituíram-se com maior evidência a partir desta perspectiva relacionada ao saber/poder: a caserna, a prisão, o mosteiro, o hospício, a escola e a fábrica. Este último, nosso espaço de interesse. Como se pode perceber, o problema de pesquisa traz consigo uma proposta conceitual que faz menção a muitos elementos do pensamento foucaultiano. Contudo, para este momento, é importante apresentar como integrantes do marco teórico cinco elementos essenciais: a tecnologia, o discurso, as práticas discursivas, o saber e o poder.

Em relação a tecnologia, adotamos a perspectiva teórica na concepção de Foucault. Para o autor existiriam duas tecnologias essenciais, das quais derivariam outras representadas como estratégias do poder: uma tecnologia 
regulamentadora da vida e uma tecnologia disciplinar. Tal concepção possui em suas raízes a noção de que cada técnica de produção em cada época estaria a exigir uma conduta individual, que exigiria não só aptidões, mas também determinadas atitudes. Assim, a tecnologia, mais do que um instrumental para a produção estaria também inserida no processo da construção de subjetividades. Para Foucault (1982) estas tecnologias derivariam para quatro conjuntos de técnicas específicas: 1 ) as técnicas de produção que nos permite produzir, transformar e manipular objetos; 2) as técnicas de sistemas e signos, que permitem a utilização de signos, de sentidos, de símbolos ou de significação; 3) as técnicas de poder, que determinam a conduta dos indivíduos, submetendo-os a certos fins ou à dominação, objetivando o sujeito; e 4) as técnicas de si, que permitem aos indivíduos efetuarem, sozinhos ou com a ajuda de outros, um certo número de operações sobre seus corpos, suas almas, seus pensamentos, suas condutas, seus modos de ser; de transformarem-se a fim de atender um certo estado de felicidade, de pureza, de sabedoria, de perfeição ou de imortalidade.

Elementos deste marco teórico possibilitaram analisar o sujeito e o corpo social enquanto espaços e objetos do saber e do poder. Porém, admitimos por poder, não um elemento exclusivamente repressor e sujeito a propriedade, mas como algo que não se dá, nem se troca, nem se retoma, mas que circula, se exerce. Do mesmo modo que esta concepção não está vinculada tão somente a uma perspectiva econômica ou política, mas sim, a uma relação de força que está em disputa, numa constante relação de reprodução e resistência (FOUCAULT, 1982).

Assim, explicitados os elementos do marco teórico que fundamentaram o estudo, passamos a expor a abordagem metodológica utilizada. Diante de seus objetivos, a característica essencial desta abordagem foi a permanente busca do diálogo. Deste modo, as possibilidades para análise e interpretação das relações de saber e poder no contexto das fábricas analisadas foram percebidas como uma construção social e ativa. Com este fim, recorreu-se a uma diversidade de técnicas de pesquisa que possibilitaram não apenas a criação de espaços abertos ao diálogo, mas de uma análise interpretativa orientada e ampla. Dentre tais técnicas, utilizamos a observação indireta, entrevistas semi-estruturadas, análise de imagens e análise de documentos. Esta perspectiva trouxe consigo um grande desafio, qual seja o desafio da 
linguagem, de significado sempre insuficiente, engendrada num contexto cultural saturado de significações que implicam diretamente em uma tomada de posição (FARACO, 2003).

Destacamos as duas principais técnicas de pesquisa utilizada: as observações e as entrevistas. O processo de observação ocorreu principalmente nos setores mais vinculados a produção. Durante o processo foram realizadas fotografias que permitiram a análise do espaço das fábricas a fim de registrar as etapas dos processos de produção. Esta fase de pesquisa foi salutar, pois permitiu uma aproximação com as fábricas analisadas, essencial na preparação da fase que se seguiria, qual seja, as entrevistas. Estas, por sua vez, foram realizadas a partir de um roteiro semiestruturado e aplicadas em todos os níveis hierárquicos das fábricas. Após transcritas, para as análises, foram criados dois grupos de sujeitos: Grupo A composto por sujeitos pertencentes a setores estratégicos e táticos; e Grupo B - composto por trabalhadores do chão de fábrica ou setores operacionais.

\section{A reestruturação produtiva e a renovação do controle social}

Para o estudo proposto, consideramos elementar pensar a reestruturação produtiva inserida no viés discursivo para a renovação do controle social, tendo em vista a histórica resistência dos trabalhadores à racionalidade determinada para a organização do processo de trabalho. Um fator que incidiu sobre os limites do taylorismo-fordista também decorreu da relação entre produtividade e a resistência dos trabalhadores no desenvolvimento de novas técnicas, em virtude de ações que de certo modo terminaram por excluir os trabalhadores da luta pela produtividade e pela qualidade, na medida em que as contradições, desigualdades e o estranhamento em relação a estes objetivos foram acirradas (ANTUNES, 1997). Tais fatores se somaram a uma perspectiva complexa em torno de um cenário econômico mundial em crise.

O que se pode interpretar deste panorama é que o modelo de produção taylorista-fordista estava até então ancorado a uma base de rigidez que agora já não poderia sustentar-Ihe. Como esclarece Harvey (2003) esta rigidez estava atrelada tanto às formas de investimento quanto aos mecanismos de produção que impediam a flexibilidade de planejamento e crescimento impostos pelos novos rumos determinados pelos mercados 
globalizados. A palavra de ordem para o momento, "flexibilidade" tornou-se alvo de diversas experiências que repercutiram tanto para a organização do trabalho como para a vida social de modo geral, configurando um novo modo de acumulação: a acumulação flexível, sem, contudo, deixar de mesclar-se a processos como o artesanato e a manufatura.

Invernizzi (2000), explica como esta nova organização, a partir de uma redefinição na divisão do trabalho, repercutiu para as alterações no contexto do controle social. Para a autora, neste tipo de organização, o controle já é exercido de modo direto e coercitivo sobre o trabalho individual, como no modelo taylorista-fordista. Mas opera-se uma transição para o controle via organização do trabalho, sustentado na responsabilidade e autonomia do trabalhador frente a seu trabalho, no auto-controle e no controle entre os próprios trabalhadores. Neste sentido, uma das evidências desta tendência é a expressiva redução das camadas de supervisores na estrutura de diversos segmentos produtivos, propiciando a chamada horizontalização das hierarquias organizacionais. Este contexto pode ser representado pela intensa implementação de processos voltados para a qualidade e a produtividade. Neste sentido, não se pode afirmar que houve evidentemente uma superação do sistema taylorista-fordista, mas um processo de hibridização, inclusive com outros processos produtivos como o artesanato e a manufatura.

No entanto, pensamos que as inovações não poderiam estar restritas apenas às transformações relacionadas aos equipamentos da microeletrônica, por exemplo, mas também deveriam compreender as tendências de reorganização do trabalho, principalmente no que tange aos aspectos sociais e econômicos. As decorrentes modificações no mercado, nas regras de negociação coletiva, na reorganização dos departamentos das grandes empresas, nas intervenções do estado e nas políticas econômicas, estavam sendo introduzidas de forma tão rápida quanto às inovações em termos de outros artefatos (ANTUNES, 1997).

Do contexto da reestruturação produtiva, emergiu a partir de diversas fontes, uma elaboração discursiva orientada por uma gama de estratégias para o controle da força de trabalho, enfáticas em evidenciar a importância do "trabalho em equipe" e da "gestão participativa". Algumas hipóteses podem ser traçadas para justificar estas alterações. Inicialmente, melhorar o relacionamento no interior das fábricas permitiria uma certa estabilização da 
mão-de-obra, possibilitando um maior investimento na qualificação dos trabalhadores, contudo, voltada para a constituição de um perfil profissional participante, consciente, responsável e sobretudo flexível às demandas do mercado.

Outra circunstância é o esforço empresarial na utilização de programas ou treinamentos de motivação ou comportamentais. Esta preocupação residia muito mais em tornar os trabalhadores mais cooperativos para com as estratégias das gerências do que a formação de profissionais mais qualificados (ANTUNES, 1997; HARVEY, 2003). Assim, as inserções de técnicas desta natureza evidenciaram o caráter disciplinador dos discursos em circulação e que enfraquecem as bases das noções relacionadas aos modelos de gestão participativa. Se por um lado, as estratégias do período indicaram uma fase de estabilização da mão-de-obra, por outro, as demissões em massa provocadas pelo fechamento de fábricas, automatização de setores inteiros e do descarte dos trabalhadores de mais idade, menor qualificação ou dos que não se adaptavam ao processo de reestruturação, inquestionavelmente limitam a noção de participação.

\section{O contexto da reestruturação produtiva nas fábricas pesquisadas}

Analisar o processo de reestruturação produtiva nas fábricas apenas tornouse possível após um cuidadoso processo de observação do cotidiano das mesmas. Foi por meio destas observações que se puderam verificar as singularidades e as semelhanças em ambas as fábricas, a partir de suas práticas e do conjunto de narrativas que compunham seus discursos, coletados durante o processo de entrevistas.

No caso da Fábrica B, fábrica produtora de fogões a lenha, dois elementos estão permanentemente presentes no viés discursivo em torno da reestruturação produtiva: o processo de urbanização do país e a tradição. Este processo esteve embricado a uma profunda alteração das relações sociais e dos padrões de consumo. No caso do tipo de fogões utilizados pela população, essas alterações foram determinantes para a reestruturação do segmento. Neste contexto, a fábrica percebeu uma intensa redução do seu mercado consumidor, dados os diversos fatores desta conjuntura imposta, onde a "cidade" passou a ditar novos padrões de consumo e outros 
ritmos de tempo, trazendo algumas limitações, que invariavelmente estavam presentes nas narrativas dos sujeitos de pesquisa.

Este processo de urbanização do país, também implicou para uma alteração nos modelos de habitação e da inviabilização da utilização do produto principalmente no meio urbano, diminuindo sensivelmente o seu mercado consumidor. Uma segunda situação é o ingresso da mulher no mercado de trabalho e as decorrências deste processo para as transformações dos papéis relacionados à família, por exemplo. De acordo com estudos de Silva (2005), entre os períodos de 1985 a 2003, a participação feminina na população economicamente ativa passou de 33,5\% para $42,7 \%$.

Outro elemento recorrente no viés discursivo na Fábrica B é a tradição. A partir das observações e das narrativas pôde-se detectar que a tradição está fortemente vinculada não somente ao processo de produção, como também no contexto da reestruturação produtiva imprimindo um ritmo mais lento para a reestruturação do segmento de fogões a lenha. Ao contrário das vias normais da indústria de linha branca, poucas alterações foram percebidas e narradas no caso da Fábrica B. Até mesmo mudanças implementadas em relação ao design do produto, planejadas no sentido de reduzir tempos de produção e de matéria-prima empregada, não obtiveram êxito diante de padrões de consumo bastante resistentes, que provocaram a retomada da produção de modelos tradicionais. Além disso, o que se tornou evidente foi uma noção de tradição que está também na base do processo produtivo e de organização do processo de trabalho. Uma das singularidades deste processo caracteriza-se principalmente pela atividade fabril predominantemente manual associada aos moldes industriais, presente na manufatura de peças de ferro fundido, que constituem a maior parte do fogão a lenha, assim como na montagem dos fogões. Talvez este seja o aspecto mais importante acerca da reestruturação produtiva observada na Fábrica B: existência de permanências de modelos produtivos muitas vezes considerados ultrapassados como o modelo de produção artesanal e manufatureiro.

Por sua vez, no caso da Fábrica A - fábrica de fogões a gás, pôde-se perceber uma reestruturação produtiva bastante dinâmica se comparada a Fábrica B - fábrica de fogões a lenha. O ponto de partida para a reestruturação da fábrica $A$ consistiu num processo de mudança nos padrões 
culturais da fábrica. Os indícios captados durante os processos de entrevista e de observação indicaram uma transição entre uma cultura denominada "familiar", para a construção de uma cultura denominada "profissional". No caso da fábrica investigada os rumos para uma transição de cultura paternalista para uma cultura profissional, com foco no indivíduo, colaborador e flexível, conforme as demandas da acumulação flexível deramse por meio de duas ações principais. A primeira referiu-se à retirada dos proprietários do comando da empresa, que passaram a figurar num Conselho Gestor criado para a transição do período. A fábrica passou a ser gerida por profissionais reconhecidos pelo mercado da indústria de linha branca, com vários anos de experiência, principalmente com passagens por conglomerados estrangeiros localizados na região metropolitana de Curitiba e interior de São Paulo. O que se pode verificar é que juntamente com uma mudança nos padrões culturais da empresa, de modo estratégico esta optou pela contratação de profissionais que pudessem agregar à empresa experiências de caráter organizacional e de produção que haviam vivenciado nas empresas concorrentes.

A segunda ação proposta foi a substituição de funcionários mais antigos da empresa, de modo geral, criando um cenário apto a mudanças mais rápidas e numa tentativa de minimizar as possíveis resistências arraigadas à cultura da fábrica. Deste modo, é possível afirmar que mais do que apenas uma mudança nos padrões culturais, estas alterações estão em permanente diálogo com a intenção de um processo de alavancagem tecnológica, no sentido da renovação não apenas do processo de produção, mas também do controle da força de trabalho, que na materialidade foram implementadas a partir de diversos dispositivos, essencialmente voltados à equipamentos de controle direto da produção e indiretamente da organização do trabalho e de programas de qualidade. Tal alavancagem, associada aos processos de transformação da cultura da fábrica, inicialmente esteve associada à modernização da maquinaria utilizada na produção. Contudo, esta alavancagem estava associada a três pilares fundamentais: a) a renovação de uma política de controle; b) a reorganização das formas de produção e c) a implantação de programas de qualidade.

Quanto a renovação de uma política de controle, esta fora viabilizada principalmente pela introdução de programas específicos de controle da produção, principalmente por softwares de informatização e processamento de dados. A renovação de uma política de controle neste panorama está 
evidentemente articulada a uma perspectiva histórica acerca da produção e da organização da força de trabalho inserida na sociedade capitalista, que retrata a qualificação de um viés discursivo cujo desejo é o de constantemente mensurar a realidade (CROSBY, 1999). Contudo, esta mensuração de certa maneira está vinculada à atividade de decompor os processos, as atividades e as tarefas, a fim de buscar evidências ou indícios do "erro" ou de focos de "anomalias"; é preciso também vigiar, legitimamente, posto que a vigilância torna-se um operador econômico decisivo, na medida em que é ao mesmo tempo uma peça interna no aparelho de produção e uma engrenagem específica do poder disciplinar (FOUCAULT, 1975).

Há deste modo, uma renovação da política de controle na medida em que a presença física do fiscal presente na produção é substituída pela inverificável e eficiente vigilância operacionalizada pelo computador ou pelo próprio trabalhador. Assim, a ampliação do poder de decisão do trabalhador ou uma maior autonomia, estaria a trabalhar contra ele, na medida em que ele deveria ser fiscal de si próprio e dos demais trabalhadores, enfraquecendo laços históricos relacionados à idéia de classe. Esta política de controle renovada é condição essencial para a introdução das experiências de reorganização das formas de produção que aconteceram na empresa, no caso a alteração do layout, para a formação de células de produção. Além da situação inerente à divisão espacial, uma situação que chamou a atenção refere-se ao controle do trabalho exercido pelo próprio operador. Para este caso, percebe-se a tendência da atual organização do controle da produção, qual seja, a transferência aos próprios trabalhadores de uma função historicamente patronal, o controle. Esta transferência fora permitida principalmente pela reestruturação da produção em células, implementadas juntamente com outras ferramentas de controle como o JIT just in time e o kanban.

Em associação à produção em células, foram implementadas outras ferramentas de controle como o JIT - Just in time e o kanban. No contexto da reestruturação produtiva, estas ferramentas têm sido estratégias diretamente voltadas à redução dos tempos de produção. No caso das narrativas coletadas na fábrica, percebe-se que este processo ocorreu tanto em seu contexto interno quanto num processo de derivação para os fornecedores e clientes externos. Ainda em relação às ocorrências na fábrica, 
percebe-se que esta ferramenta também fora utilizada de modo a "clarear" os processos de logística, dentre outros, o que trouxe à tona, algumas "anomalias" existentes no processo produtivo. Com a implementação do Just in time ao processo produtivo, o kanban também foi associado, no intuito de garantir uma maior padronização acerca da produção, facilitando estes controles.

\section{Manifestações do saber e do poder mediadas pela tecnologia}

No decorrer da construção do estudo, pôde-se constatar que o contexto da reestruturação produtiva foi o cenário para que as manifestações entre as relações de saber e poder pudessem ser verificadas com maior efetividade. Neste sentido, três manifestações foram percebidas e analisadas com maior profundidade. A primeira é evidenciada a partir das trajetórias pessoais dos sujeitos de pesquisa, qual seja a grande ocorrência de trabalhadores de origem rural no contexto fabril pesquisado. A segunda, por sua vez, é a manifestação que se refere às alterações relacionadas ao trabalho feminino nas fábricas e a terceira relacionada à organização do tempo e espaço no ambiente fabril. Foi a partir destas manifestações que se buscou analisar como são estabelecidas algumas relações entre o saber e o poder.

A primeira relação reside no grande número de trabalhadores de origem rural presente nas fábricas investigadas. Estes trabalhadores localizavam-se principalmente entre os membros do Grupo B - grupo de trabalhadores do chão de fábrica e possuíam duas trajetórias distintas. Alguns eram filhos de pequenos proprietários rurais, que buscavam o meio urbano a fim de conseguirem empregos na indústria, com o objetivo de prosseguir com os estudos ou então eram pequenos proprietários rurais que buscavam no emprego na indústria uma complementação de renda, apesar de manterem atividades como a agricultura familiar.

Em relação a este aspecto, merece maior detalhamento a perspectiva dos gestores das fábricas (Grupo A) em relação aos trabalhadores de origem rural. Neste sentido, em várias situações, em ambas as fábricas o perfil do trabalhador de origem rural é comparado ao perfil do trabalhador urbano. A partir das percepções dos gestores, o trabalhador rural tem na maior parte das vezes, uma escolaridade baixa, mas é mais "dedicado" ao trabalho, tem 
menor sofrimento físico, por estar mais acostumado ao trabalho braçal e menor resistência aos processos de mudança na empresa. Em contraponto, o trabalhador urbano, na percepção dos gestores tem uma escolaridade maior, mas é menos "dedicado" ao trabalho, além de não adaptar-se tão facilmente aos trabalhos mais braçais, que demandem maior força física. Além disso, o trabalhador urbano é visto como mais resistente às mudanças quotidianas da empresa por demitir-se mais facilmente do emprego diante da maior facilidade de encontrar novos postos de trabalho na cidade.

Assim, uma situação importante a ser analisada, presente em ambas as fábricas, é o que diz respeito ao rendimento e ao perfil comportamental do trabalhador de origem rural sugerido na maior parte das narrativas. De modo geral, o viés discursivo caracterizou-os como trabalhadores de alto rendimento e que imporiam menor resistência aos processos de flexibilização e reestruturação da produção. Contudo, este discurso em torno da passividade dos trabalhadores de origem rural, é permanentemente desconstruído pelas próprias narrativas dos trabalhadores. Neste sentido, é possível verificar que no contexto do Sudoeste do Paraná, região onde estão localizadas as fábricas, esta apatia não é fidedigna aos processos históricos de luta pela terra e pela melhoria das condições de vida da população rural. No caso das fábricas investigadas, estes processos de resistência dos trabalhadores de origem rural se manifestam fortemente no cotidiano, principalmente pela recusa na aceitação de uma racionalidade produtiva que suprime as possibilidades de pensar a execução das atividades e onde é imperativa a disciplina do tempo e do espaço.

Um segundo aspecto relacionado ao saber e o poder no contexto das fábricas refere-se ao trabalho feminino. Contudo, as alterações no contexto do trabalho feminino nas fábricas podem ser analisadas, inseridas e em diálogo com as perspectivas de gênero. Adotamos por gênero, a definição estabelecida por Hirata, qual seja, "uma construção social, cultural e histórica do masculino e do feminino" (2003, p. 148). Além disso, as relações de gênero no contexto da sociedade, de modo histórico tem sido representadas num feixe de relações de poder, de jogos de verdade e de constituição e transformação de saberes.

No caso da Fábrica A (de fogões a gás), em períodos anteriores, a participação de mulheres na composição da força de trabalho era bastante representativa, principalmente alocadas na linha de montagem e serigrafia. 
Contudo, em função do surgimento de várias situações de afastamento das atividades em decorrência de LER/DORT (Lesões por esforços repetitivos/Distúrbios ósteomusculares resultantes do trabalho), que promoveram diversas ações indenizatórias, processos de aposentadorias por invalidez e a necessidade de readequação em outros postos de trabalho, grande parte do quadro de funcionárias foi demitido, restando apenas alguns postos de trabalhos onde estudos demonstraram a existência de pequeno risco para a ocorrência de doenças laborais.

Já no caso da Fábrica $B$, que em períodos anteriores não possuíam nenhum posto de trabalho junto à produção pertencente às mulheres, por recomendação de profissionais da Fábrica $A$, que já haviam trabalhado em outras empresas do setor de linha branca, passaram a contratar mulheres exclusivamente para trabalhos de limpeza e inspeção do produto final, alocadas no fim da linha de montagem. Ainda que a primeira vista, este crescimento da participação feminina na mão-de-obra da fábrica analisada seja pequeno, não se pode considerá-lo insignificante. Neste sentido, o ingresso de mulheres em determinadas atividades que anteriormente eram realizadas por homens, mesmo em setores de limpeza e inspeção foram importantes no sentido de valorizar saberes considerados femininos em relação ao processo produtivo industrial. Associados as políticas de controle de qualidade implementadas na fábrica, as habilidades femininas tornaramse condição para a contratação em determinados postos de trabalho.

Esta perspectiva em torno do trabalho feminino no contexto da fábrica analisada, inevitavelmente traz à tona a discussão em torno da divisão sexual do trabalho. O que se percebe no contexto das fábricas é a alocação das mulheres em funções voltadas principalmente para o atendimento a clientes, inspeção e limpeza dos produtos. No contexto da divisão sexual do trabalho, as fábricas analisadas apresentam indicativos semelhantes com as pesquisas mais recentes realizadas sobre o trabalho feminino na fábrica. De acordo com estudos de Hirata (2003) o trabalho feminino no contexto fabril está organizado em diálogo com as relações entre técnicas e os equipamentos utilizados no processo produtivo. Neste aspecto, geralmente as tarefas femininas são predominantemente manuais; a destreza e a rapidez das mulheres é razão para a sua utilização nas linhas de montagens ou ainda, a modernização dos equipamentos tende a excluir as mulheres de sua utilização, ao passo que se tratando de maquinaria mais comuns a mão-deobra utilizada é feminina. 
Além das funções menos qualificadas no chão de fábrica, onde foram identificados os postos de trabalhos ocupados por mulheres, nos setores administrativos investigados, estas geralmente estão alocadas em funções de assistência ou demais atividades que não estão inseridas nos níveis mais estratégicos das fábricas (os de estratégia e planejamento, por exemplo), como nos setores de vendas e atendimento aos clientes. Como exceção, apenas numa das empresas foi localizada uma mulher que exerce a função gerencial, sendo que esta apresentava o melhor nível de qualificação entre as mulheres (pós-graduação). Esta realidade, porém, é justificada pelos gestores pelo nível de qualificação das mulheres. Para estes, na medida em que as trabalhadoras forem se qualificando terão maiores facilidades ao acesso de cargos associados aos níveis hierarquicamente mais elevados.

Um terceiro aspecto importante a ser considerado nas relações entre saber e poder no contexto das fábricas investigadas é a relação entre tempoespaço. Neste sentido, nos referimos também ao arranjo dos corpos na produção. Foi possível constatar que em setores diretamente ligados à produção, o arranjo dos trabalhadores está em consonância a uma racionalidade de organização que tende a dividir o espaço e funções de acordo com critérios de faixa etária. No caso de ambas as fábricas, os setores de montagem eram compostos em sua maioria por trabalhadores bastante jovens, enquanto que nos setores de estamparia, esmaltação e fundição, por exemplo, os trabalhadores possuíam idade aparentemente mais avançada. Esta situação está em pleno diálogo com as exigências em torno da produtividade e da redução dos tempos de produção.

Esta perspectiva em torno das metas de produção e da redução dos tempos de trabalho está também evidenciada nos diversos controles realizados por supervisores e pelos próprios trabalhadores, ao exporem em tabelas de controles, espalhadas por todo o setor produtivo o ritmo da produção. Todavia, algo que marcadamente surgiu nas narrativas dos trabalhadores, se refere a esta disciplina do tempo e do corpo imposta pela linha de produção, bastante fragmentada e pelo trabalho repetitivo e monótono.

\section{Considerações Finais}


A implantação destas novas estratégias tanto de produção, como de controle do trabalho e da força de trabalho, imbricadas no viés discursivo da reestruturação produtiva, também interessada na renovação do controle social, como uma das demandas prementes da acumulação flexível, repercutiram para novas táticas de resistência por parte dos trabalhadores, a partir das transformações entre saberes e poderes.

É possível considerar que a reestruturação produtiva, tanto em aspectos mais globais quanto relativos às fábricas investigadas, constituiu-se de uma profunda renovação do controle social, não apenas com vistas a readequação do modo de produção capitalista face a sua permanente crise, ou as "novas demandas" sugeridas e justificadas pelos critérios de competitividade suscitadas no período, mas principalmente pela reestruturação/renovação do controle social com vistas a uma outra organização da força de trabalho e da produção.

Destes processos de reestruturações produtivas, é que se torna também possível perceber as relações entre saberes e poderes não apenas sendo estabelecidas, mas também transformadas. Assim, no contexto da produção nas fábricas analisadas foi possível verificar uma espécie de tecnologia do poder, em diálogo com as tecnologias de produção. Essa tecnologia do poder, como pôde verificar-se está arquitetada e estruturada sobre uma rede de saberes e poderes que quotidianamente são criados e transformados pelos sujeitos em constituição.

Outra indicação refere-se a introdução da maquinaria e da organização do trabalho e da produção de modo mais flexível, além de técnicas de gestão voltadas a uma política de controle tanto da produção quanto da força de trabalho que representou a desqualificação de saberes, como o saber dos trabalhadores, por exemplo, para qualificar o saber fazer da máquina, agora operada pelo trabalhador. Contudo, outros saberes foram sendo criados e transformados nesta conjuntura, inclusive por meio de táticas de resistência. Estas táticas de resistência no caso dos trabalhadores restaram demonstradas durante a pesquisa principalmente representadas pelo absenteísmo, pela alta rotatividade da força de trabalho, pela resistência ao se comprometer com os objetivos mais específicos da produtividade e da qualidade requeridos pelos gestores no contexto das fábricas. 


\section{Referências}

ANTUNES, Ricardo. Adeus ao Trabalho? Ensaio sobre as metamorfoses e a centralidade do mundo do trabalho. 4 ed. São Paulo: Cortez; Campinas, SP: Editora da Universidade Estadual de Campinas, 1997.

CROSBY, Alfred W. A mensuração da realidade: a quantificação e a sociedade ocidental (1250-1600). São Paulo: UNESP, 1999.

FARACO, Carlos A. Linguagem e Diálogo: As idéias lingüísticas do círculo de Bakhtin. Curitiba: Criar, 2003.

FOUCAULT, Michael. Vigiar e Punir. Rio de Janeiro: Graal, 1975.

Microfísica do Poder. Rio de Janeiro: Graal, 1982.

HARVEY, David. Condição Pós Moderna: uma pesquisa sobre as origens da mudança cultural. São Paulo: Loyola, 2003.

INVERNIZZI, Noela. Novos rumos do trabalho: mudanças nas formas de controle e qualificação da força de trabalho brasileira. ANO. 00 f. Tese (Doutorado) - DPCT-IG, Unicamp. Campinas, 2000.

SILVA, Nanci. S. Reestruturação produtiva e gênero: um estudo de caso em duas empresas de linha branca. ANO. 00 f. Tese (Doutorado) - DPCTIG, Unicamp. Campinas, 2005. 